\title{
Energy in Focus
}

\author{
Sean Shaheen \\ Editor-in-Chief, Journal of Photonics for Energy
}

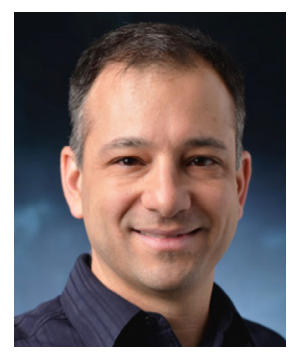

JPE was founded as a venue for emerging concepts in photovoltaics, energyefficient lighting, and other topic areas fundamental to the advancement of sustainable energy technologies. The need for continued, and in fact accelerated, progress has never been more pressing than now, as evidenced by the most recent report from the Intergovernmental Panel on Climate Change, ${ }^{1}$ among countless other data points that motivate us to rapidly enact large-scale change in global energy systems.

JPE is committed to doing its part by publishing outstanding work that illustrates how insightful and creative approaches to photonics can advance critical technology areas. Energy consumption in buildings is one of them, as residential and commercial buildings consume $\sim 40 \%$ of the total energy consumption ${ }^{2}$ and $\sim 75 \%$ of total electricity ${ }^{3}$ in the United States and similarly around the globe. ${ }^{4,5}$ Our recent special series on Radiative Cooling ${ }^{6}$ brings to light new photonic materials and metamaterials that manage the thermal emission of photons from building rooftops in scalable, cost-effective ways. There is tremendous potential for such technologies to impact our global energy usage - in hindsight, why did we not start developing these concepts sooner? Part of the answer lies in that the field is now reaching a point of convergence of precision design, fabrication, and characterization of high performance, nanostructured photonic materials. However, part of the answer I believe lies in that simply there is renewed urgency for all of us to truly advance critical technologies.

Continuing this theme, the upcoming JPE Special Series on Novel Photovoltaic Device Architectures $^{7}$ aims to publish emerging research on future high efficiency concepts and devices that make use of novel materials as well technological advances in bifacial and buildingintegrating photovoltaics that are having impact right now. We invite you to contribute your research on these topics and other areas within JPE's scope, as we all bring our own sense of urgency to bear on advancing renewable energy science and technologies.

\section{References}

1. Intergovernmental Panel on Climate Change, Climate Change 2021: The Physical Science Basis. Contribution of Working Group I to the Sixth Assessment Report of the Intergovernmental Panel on Climate Change, V. Masson-Delmotte et al., Eds., Cambridge University Press (in press) https://www.ipcc.ch/assessment-report/ar6/ (2021).

2. U.S. Dept. of Energy, "Building efficiency report," 2013, https://www.energy.gov/downloads/ building-efficiency-report (accessed September 2021).

3. M. Neukomm, V. Nubbe, and R. Fares, "Grid-interactive efficient buildings," U.S. Dept. of Energy Technical Report Series, 2021, https:/www.nrel.gov/docs/fy20osti/75470.pdf.

4. B. Hojjati, "Global energy consumption driven by more electricity in residential, commercial buildings," U.S. Energy Information Administration, 2019, https://www.eia.gov/todayin energy/detail.php?id=41753 (accessed September 2021).

5. UN Environment and International Energy Agency, "Towards a zero-emission, efficient, and resilient buildings and construction sector: global status report 2017," 2017, United Nations Environment Programme, https://www.worldgbc.org/sites/default/files/UNEP\%20188_ GABC_en\%20\%28web\%29.pdf (accessed September 2021).

6. "JPE Special Series on Radiative Cooling," https://www.spiedigitallibrary.org/jpe-specialseries-radiative-cooling (accessed September 2021).

7. “Call for papers: JPE Special Section on Novel Photovoltaic Device Architectures," https:// www.spiedigitallibrary.org/journals/journal-of-photonics-for-energy/call-for-papers\#Novel PhotovoltaicDeviceArchitectures (accessed September 2021).

(C) 2021 Society of Photo-Optical Instrumentation Engineers (SPIE) 